\title{
Training to reduce emergency responders' perceived overdose risk from contact with fentanyl: early evidence of success
}

\author{
Rachel P. Winograd ${ }^{1 *}$ (D, Sarah Phillips ${ }^{1}$, Claire A. Wood ${ }^{1}$, Lauren Green ${ }^{1}$, Brandon Costerison ${ }^{2}$, \\ Jeremiah Goulka ${ }^{3}$ and Leo Beletsky ${ }^{3}$
}

\section{Introduction}

Overdose deaths involving opioids in the USA have skyrocketed $41.5 \%$ since 2010 [1], with a provisional count of over 47,105 deaths from August 2018 to August 2019 [2]. Synthetic opioids, particularly fentanyl, have driven deaths in recent years due to their high potency and low overdose threshold. Indeed, death statistics in Missouri suggest over $75 \%$ of fatal opioid overdoses involved fentanyl in 2018 [3].

In Missouri, emergency medical services (EMS) personnel and law enforcement officers (LEOs) are called to respond to the increasing numbers of opioid overdoses. Emergency responders report frequent occupational safety concerns related to illicit drug use [4]. One common fear is needle stick injury and the subsequent potential risk of contracting infectious diseases [5]. Additionally, emergency responders express concern for their own safety during overdose reversals, including purported instances of aggression and combativeness on the part of the survivor $[6,7]$.

With the relatively recent surge in fentanyl-related overdoses, a new occupational safety concern has emerged among emergency responders: the fear of overdosing from touching fentanyl [8]. In 2017 alone, over 150 media reports describing first responder exposures to opioids surfaced [9]. Reports of overdose due to fentanyl contact among first responders [10-13] have been repeatedly refuted by medical experts [14-16]. Yet, mixed messages from the US government agencies [17] and their prominence in media outlets have catalyzed

\footnotetext{
* Correspondence: rachel.winograd@mimh.edu

${ }^{1}$ Missouri Institute of Mental Health, University of Missouri, St. Louis, Missouri, USA

Full list of author information is available at the end of the article
}

the spread of misinformation about the risks of accidental fentanyl contact. The high level of concern about this theoretical threat has been especially stark in the context of the COVID-19 pandemic, particularly in the USA, when police have reportedly expressed comparatively little anxiety about contracting the potentially deadly virus [18].

There has been an increase in products marketed to address the fear of fentanyl, including fentanyl exposure prevention kits [19, 20], gloves marketed to protect against fentanyl [21], other fentanyl-resistant gear and screening devices [22], and fentanyl clean-ups [23]. Additionally, legislators in the USA have proposed the Providing Officers with Electronic Resources (POWER) Act that would fund state and local enforcement agencies to purchase fentanyl screening devices to protect officers from incidental exposure [24]. However, because these screening procedures require the use of class B hazmat suits [25] and other equipment prior to responding to the overdose, these precautions could potentially delay the time-sensitive, lifesaving administration of naloxone and rescue breathing.

Concerns about fentanyl exposure continue to spread despite a clear consensus from medical experts that overdose from incidental skin contact is a medical impossibility $[14,15]$. Indeed, this claim has been officially debunked by the American College of Medical Toxicology and the American Academy of Clinical Toxicology [16] and the National Occupational Safety and Health with the CDC [26]. A drug policy advocate has also disproven this myth by holding fentanyl powder in his hand without consequence and widely circulating the internet footage [15]. Researchers who study reported overdoses from fentanyl exposure among emergency 
responders have explained that cases documented thus far can best be attributed to the "nocebo effect"-a phenomenon in which individuals believe they have encountered a toxic substance and therefore experience the expected symptoms of exposure [27]. This is consistent with our broader understanding of occupational wellness and mental health-or lack thereof-among first responders [28]. When individuals are already operating under acute stress and with few mental health reserves, fear of overdose from touching fentanyl could serve as an additional stressor.

To our knowledge, only one study has examined emergency responders' perceptions of risk associated with brief exposure to fentanyl. In their study of 247 first responders in New York, Persaud and Jennings found $80 \%$ of responders believed "briefly touching fentanyl could be deadly." Based on these findings, the authors concluded trainings should incorporate accurate information about fentanyl risk and overdose response. To date, no studies have explored the extent to which these beliefs are modifiable through training and education.

As part of a broader effort to improve community access to naloxone, the authors of the current study developed comprehensive training for emergency responders on recognizing and responding to an overdose, basic tenets of addiction, and the roles of treatment and harm reduction strategies. Because unfounded fears about incidental contact with fentanyl could result in delays in responding to overdoses, we incorporated medically accurate information regarding fentanyl exposure into this existing overdose education and response training program. In addition to increasing knowledge and improving attitudes towards overdose recognition and response scenarios $[29,30]$, we aimed to decrease participants' endorsement of the pre- and post-training survey statement "I can overdose from touching fentanyl."

\section{Methods}

\section{Participants}

Between January and August 2019, project staff conducted eight LEO trainings and three EMS trainings for a total of 11 trainings reaching 200 participants. All trainings were conducted in the Eastern Region of Missouri, which consistently demonstrates the highest drug overdose rates in the state [3]. Though all trainings were tailored for professional emergency responders, other professionals were allowed to attend, though their survey data was omitted $(n=17)$. For this study, 113 participants identified as an LEO or Security Officer "LEO group" and 27 participants identified as an EMS, EMT, or Fire Department Worker "EMS group", for a total of 140 participants.

\section{Demographics}

Demographic data were collected on the age, race, ethnicity, and gender of each participant (see Table 1).

\section{Procedure}

LEO and EMS training content included information about the nature of addiction as a chronic brain disease, harm reduction principles, concerns about "enabling" drug use (i.e., naloxone-related risk compensation [29]), the role of addiction treatment medications, and Missouri's naloxone and Good Samaritan laws, in addition to accurate information regarding the medical impossibility of overdosing from incidental skin exposure to fentanyl. The training portion addressing fentanyl misconceptions took approximately $10 \mathrm{~min}$ to present and discuss. In LEO trainings, the fentanyl information was taught by an emergency medicine physician. For EMS trainings, it was covered by the Project Manager.

Participants were consented prior to the start of each training. They were then given a paper survey including items tapping their knowledge and attitudes about a range of topics related to opioid overdose recognition and response, including but not limited to their belief that it is possible to overdose from touching fentanyl (for the purposes of this study, only this item related to fentanyl contact was analyzed and reported). Participants completed the same survey immediately following the training. The surveys were later manually entered into REDCap by a research assistant. The University of Missouri-St. Louis IRB approved this research study.

\section{Measure of belief in fentanyl exposure risk}

Before and after the training session, participants indicated their agreement with the following original item by checking either "True" or "False": "I can overdose from touching fentanyl."

\section{Statistical analyses}

We used SPSS to conduct a Fisher's exact test to assess differences in pre- and post-training item responses across the LEO and EMS groups. We then applied McNemar's test, appropriate for paired, categorical data, to assess changes in the pre- and post-training proportions of responses in the overall sample and by professional groups (LEO vs. EMS) to determine the effectiveness of brief training on reducing the false belief that one can overdose from touching fentanyl.

\section{Results}

\section{Baseline differences by profession}

On the pre-training survey, only $20.9 \%$ of all participants correctly answered "False" to the statement "I can overdose from touching fentanyl." There were differences in responses across the professional groups, with $16.8 \%$ of 
Table 1 Demographics

\begin{tabular}{llll}
\hline & Overall $(N=140)$ & LEO group $(n=113)$ & EMS group $(n=27)$ \\
\hline Mean age (SD) & $40.96(11.27)$ & $40.6(11.0)$ & $42.3(12.5)$ \\
Men & $110(79.7 \%)$ & $98(86.7 \%)$ & $12(44.4 \%)$ \\
Hispanic/Latino(a) & $5(3.6 \%)$ & $4(3.5 \%)$ & $1(3.7 \%)$ \\
Race & & & $26(96.3 \%)$ \\
$\quad$ White & $115(82.1 \%)$ & $89(78.8 \%)$ & 0 \\
$\quad$ Black & $15(10.7 \%)$ & $15(13.3 \%)$ & $1(3.7 \%)$ \\
$\quad$ Multiracial or other & $4(2.9 \%)$ & $3(2.7 \%)$ & 0 \\
$\quad$ Refused & $6(4.3 \%)$ & $6(5.3 \%)$ & \\
\hline
\end{tabular}

${ }^{1}$ Other races includes Asian, American Indian/Alaskan Native, or Native Hawaiian/Pacific Islander

LEOs and $37.0 \%$ of EMS participants answering "False" (Fisher's exact test; $p=.033$ ).

\section{Effect of brief training}

Post-training, $83.6 \%$ of all participants correctly responded "False" to the statement (a difference of $62.7 \%$ from pre-training; McNemar's test; $p<.001$ ). Within group pre-post comparisons also reached significance for both groups, with $81.4 \%$ of the LEO group (McNemar's test; $p<.001$ ) and $92.6 \%$ of the EMS group answering "False" post-training (McNemar's test; $p<$ $.001)$. This reflected an improvement of $64.6 \%$ and 55.6\% among LEO and EMS participants, respectively (see Fig. 1). The proportion of correct post-training responses did not significantly differ across professional groups (Fisher's exact test; $p=.301$ ).

\section{Discussion}

With this study, we determined that a brief, 10-min presentation and discussion of accurate information regarding the lack of risk associated with incidental fentanyl exposure reduces emergency responders' endorsement of the belief they could overdose from such contact and that such endorsements varied between LEO and EMS professional groups. Indeed, our results suggest LEOs are more likely than EMS personnel to believe they can overdose from touching fentanyl, though this difference goes away following the corrective, informational presentation. The pre-training difference is likely due to EMS personnel having more formal medical training, more experience responding to opioid overdoses than LEOs, and less interaction with police and the US Drug Enforcement Administration (DEA) colleagues who have been the driving force behind misinformation about risks of fentanyl contact [17, 31]. Overall, it is promising that both professional groups responded well to the brief informational presentation, with over $80 \%$ of LEOs and over $90 \%$ of EMS personnel demonstrating a factually accurate understanding about the lack of overdose risk from incidental fentanyl exposure in the post-training survey.

In the context of COVID-19 and the emerging threats faced by first responders, it is imperative they have accurate, up-to-date information regarding their own occupational safety. Low levels of knowledge about fentanyl, particularly among police, may reflect the

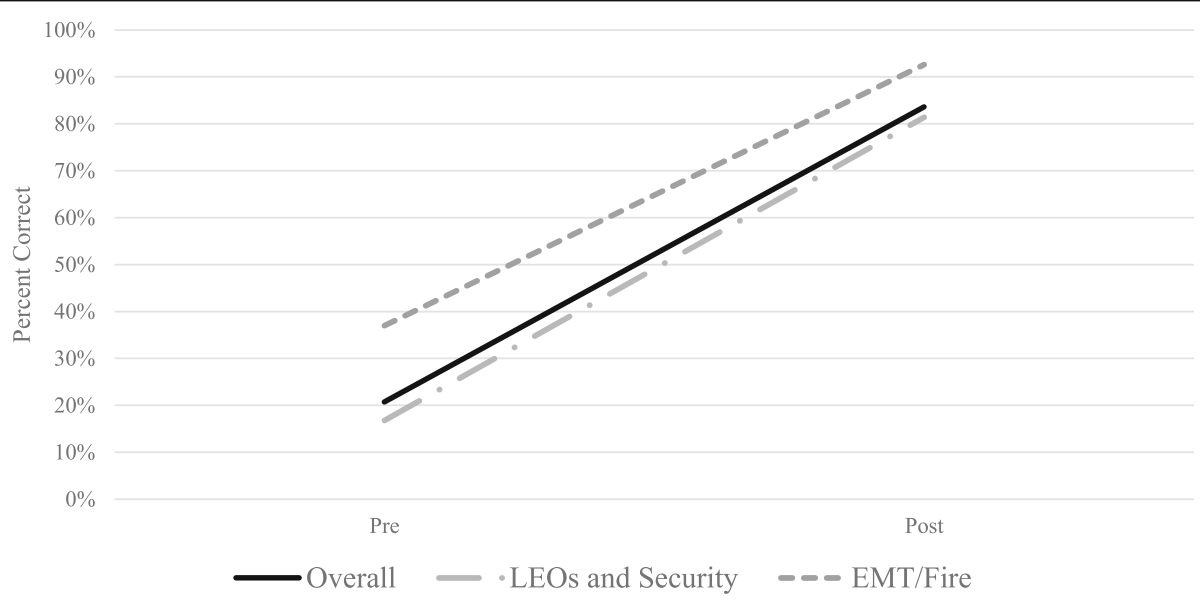

Fig. 1 Percent correctly responding "False" to the item "I can overdose from touching fentanyl" at pre-training and post-training 
relative paucity of training on occupational safety topics outside of weapons and acts of violence, as research on training pertaining to needle stick injuries has demonstrated [32].

\section{Limitations and future directions}

Despite its novelty and important implications, our study is not without its limitations, including the lack of generalizability of these findings beyond predominantly White and male emergency responders in the Midwest, as well as the relatively small sample size and simple study design, prevented us from conducting more advanced analyses, assessing confounding variables, or drawing causal inferences. Additionally, we do not have information to link responders' beliefs with their tangible behaviors in the field or the protocols of their agencies. For example, an individual police officer may understand incidental contact with fentanyl is innocuous but still be bound by departmental policy to don excessive protective gear or call for responder backup before attempting to save the life of the individual who has overdosed. Future research should explore associations between departmental protocols, individual responders' concerns about fentanyl exposure, and responders' behaviors on the scene. Also, our $2 \mathrm{~h}$ training (described in the "Methods" section) included a number of additional modules not directly related to fentanyl contact. As the information addressing fentanyl misconceptions was concise and required only $10 \mathrm{~min}$ to teach and discuss, future studies should investigate whether a brief fentanyl-focused training is sufficient to alleviate fears about fentanyl exposure.

\section{Conclusions}

To our knowledge, this study is the first to demonstrate the effectiveness of a training intervention in correcting emergency responders' potentially dangerous misconception that they can overdose from touching fentanyl, a misconception that could result in unnecessary delays when responding to an actual overdose, which requires urgent administration of naloxone and rescue breathing. With brain hypoxia and fatal overdose potentially occurring within minutes of one experiencing respiratory depression from potent opioid consumption [33], such delays in responding could result in the serious brain injury or death of the overdose victim. Emergency responder training programs about overdose recognition and response should include medically accurate information about the lack of danger of accidental skin contact with fentanyl to ensure responders act as quickly as possible when called to the scene of a life-threatening overdose.

\section{Abbreviations}

DEA: US Drug Enforcement Administration; EMS: Emergency medical services; LEO: Law enforcement officer

\section{Acknowledgements}

The authors would like to express gratitude to Vinith Ilavarasan and Rithvik Kondai for their contributions to this manuscript.

Ethics approval and consent to participate:

Participants were informed of the consent form and asked to sign prior to the start of the training, before completing the pre-training test. A research assistant confirmed that each pre and/or post-training test also had a corresponding signed consent form before tests were entered into REDCap. The University of Missouri-St. Louis IRB (registration number 00000756) approved this research study.

\section{Authors' contributions}

RW, SP, and LG conceived of the concept of the study, drafting, and editing versions of the manuscript. RW wrote the manuscript, with support from LB and JG. SP ran the analyses and interpreted the results, with guidance from CW. LB provided critical review and content additions. All authors feedback and assisted in shaping and finalizing the research and overall manuscript. All authors have read and approved the final manuscript.

\section{Funding}

This work was funded by the Substance Abuse and Mental Health Services Administration through the Prescription Drug Overdose (PDO) Grant

1H79SP022118, awarded to the Missouri Department of Mental Health, and while the work described in this article has been funded wholly or in part by the Missouri Department of Mental Health on behalf of the University of Missouri, St. Louis, it does not necessarily reflect the views of either agency.

Availability of data and materials

The datasets relevant to the current study are available from the corresponding author on reasonable request.

\section{Consent for publication}

No personal details reported on the individuals are available in this manuscript.

\section{Competing interests}

The authors declare that they have no competing interests.

\section{Author details}

${ }^{1}$ Missouri Institute of Mental Health, University of Missouri, St. Louis, Missouri, USA. ${ }^{2}$ National Council on Alcoholism and Drug Abuse, St. Louis, Missouri,

USA. ${ }^{3}$ Northeastern University, Boston, Massachusetts, USA.

Received: 27 May 2020 Accepted: 10 August 2020

Published online: 24 August 2020

\section{References}

1. NIDA. Overdose death rates | National Institute on Drug Abuse (NIDA) [Internet]. 2020 [cited 2020 Mar 12]. Available from: https://www.drugabuse. gov/related-topics/trends-statistics/overdose-death-rates.

2. Ahmad FB, Escobedo L., Rossen L., Spencer MR, Warner M, Sutton P. Provisional drug overdose data [Internet]. Natl. Cent. Heal. Stat. 2018 [cited 2020 Mar 4]. Available from: https://www.cdc.gov/nchs/nvss/vsrr/drugoverdose-data.htm.

3. Missouri Department of Health \& Senior Services. Opioids dashboard | Missouri Department of Health \& Senior Services [Internet]. Missouri Dep. Heal. Sr. Serv. 2019 [cited 2020 Mar 12]. Available from: https://health.mo. gov/data/opioids/.

4. Beletsky L, Goulka J. Project SHIELD: police education partnership to support community-based opioid overdose prevention in Missouri; 2018.

5. Arredondo J, Beletsky L, Baker P, Abramovitz D, Artamonova I, Clairgue E, et al. Interactive versus video-based training of police to communicate syringe legality to people who inject drugs: The SHIELD Study, Mexico, 2015-2016. Am J Public Health [Internet]. American Public Health Association; 2019 [cited 2019 Jun 19];109:921-6. Available from: https://ajph. aphapublications.org/doi/10.2105/AJPH.2019.305030. 
6. Taylor JA, Davis AL, Barnes B, Lacovara A V, Patel R. Injury risks of EMS responders: evidence from the National Fire Fighter Near-Miss Reporting System. BMJ Open [Internet]. BMJ Publishing Group; 2015 [cited 2019 Jun 19];5:e007562. Available from: http://www.ncbi.nlm.nih.gov/pubmed/2606 8510.

7. Wermeling DP. Review of naloxone safety for opioid overdose: practical considerations for new technology and expanded public access. Ther Adv drug Saf [Internet]. SAGE Publications; 2015 [cited 2019 Jun 19];6:20-31. Available from: http://www.ncbi.nlm.nih.gov/pubmed/25642320.

8. Persaud $E_{\text {, Jennings } C R}$. Pilot study on risk perceptions and knowledge of fentanyl exposure among New York state first responders. Disaster Med Public Health Prep. Cambridge University Press (CUP); 2019;1-5.

9. Herman PA, Brenner DS, Dandorf S, Kemp S, Kroll B, Trebach J, et al. Media reports of unintentional opioid exposure of public safety first responders in North America. J Med Toxicol [Internet]. Springer; 2020 [cited 2020 Mar 4]; 1-4. Available from: http://link.springer.com/10.1007/s13181-020-00762-y.

10. Dunn T. Officer hospitalized for fentanyl exposure during overdose call [Internet]. 2019 [cited 2020 Mar 12]. Available from: https://wbsm.com/ officer-hospitalized-for-fentanyl-exposure-during-overdose-call/.

11. Fischer C. 2 deputies possibly exposed to Fentanyl that cleaning staff found in north Harris County hotel | abc13.com [Internet]. ABC13. 2019 [cited 2020 Mar 12]. Available from: https://abc13.com/deputies-exposed-to-fentanylwhile-cleaning-up-drugs-at-hotel/5344773/.

12. York Daily Record. Officer overdoses from powder on shirt after drug arrest [Internet]. York Dly. Rec. 2017 [cited 2020 Mar 12]. Available from: https:// www.ydr.com/story/news/2017/05/15/officer-overdoses-powder-shirt-afterdrug-arrest/101712902/.

13. Reed M. East Liverpool police officer suffers fentanyl overdose from drug call [Internet]. WKBN. 2017 [cited 2020 Mar 12]. Available from: https://www wkbn.com/news/east-liverpool-police-officer-suffers-fentanyl-overdose-fromdrug-call/.

14. Faust JS, Boyer EW. Opinion | Opioid hysteria comes to Massachusetts Courts - The New York Times [Internet]. New York Times. 2018 [cited 2020 Mar 12]. Available from: https://www.nytimes.com/2018/01/23/opinion/ opioid-fentanyl-hysteria-massachusetts.html?auth=login-facebook.

15. Faust JS. Touching fentanyl is not dangerous. Could this video finally prove that? [Internet]. 2018 [cited 2020 Mar 12]. Available from: https://slate.com/ technology/2018/08/touching-fentanyl-is-not-dangerous-could-this-videofinally-prove-that.html.

16. Moss MJ, Warrick BJ, Nelson LS, McKay CA, Dubé PA, Gosselin S, et al. ACMT and AACT position statement: preventing occupational fentanyl and fentanyl analog exposure to emergency responders. Clin Toxicol. Taylor and Francis Ltd. 2018;56:297-300.

17. DEA Headquarters. DEA warning to police and public: fentanyl exposure kills [Internet]. 2016 [cited 2020 May 6]. Available from: https://www.dea. gov/press-releases/2016/06/10/dea-warning-police-and-public-fentanylexposure-kills.

18. TMZ. Cops across the country aren't scared of coronavirus, used to danger [Internet]. 2020 [cited 2020 May 6]. Available from: https://www.tmz.com/2 020/03/16/cops-police-not-afraid-coronavirus-pandemic-danger-lapd-nypd/.

19. ProPac USA. Fentanyl protection kit, disposable suit, gloves, etc. | Propac USA [Internet]. 2015 [cited 2020 Mar 12]. Available from: https://propacusa. com/product/fentanyl-protection-kit/.

20. Curplex. Single dose opioid overdose kit, black case and contents | Bound Tree [Internet]. [cited 2020 Mar 12]. Available from: https://www.boundtree. com/Kits/Opioid-Kits/Single-Dose-Opioid-Overdose-Kit-Black-Case-andContents/p/670034-KIT.

21. Medline. NitriDerm ${ }^{\oplus}$ ultra blue nitrile exam gloves - Series 157 | Innovative Healthcare Corporation [Internet]. Medline. 2018 [cited 2020 Mar 12]. Available from: https://ihcsolutions.com/product/157-nitriderm-ultra-bluenitrile-exam-gloves/.

22. Melamed S. Pa. prisons spend \$15M after guards were sickened by K2. But what if it was just in their heads? [Internet]. The Philadelphia Inquirer. 2018 [cited 2020 Mar 12]. Available from: https://www.inquirer.com/philly/news/ pennsylvania-department-corrections-prison-lockdown-drugs-k2-fentanylguards-sickness-20180907.html.

23. Winberg M. Fentanyl cleanups can cost up to $\$ 50,000$, thanks to urban legend - On top of Philly news [Internet]. Billy Penn. 2019 [cited 2020 Mar 12]. Available from: https://billypenn.com/2019/07/29/fentanyl-cleanups-cancost-50000-each-thanks-to-urban-legend/.

24. Lamb C. H.R.5871 - 115th Congress (2017-2018): POWER Act. 2018
25. Flood B. Apparent drug overdose leads to hazmat situation in Hartford fox61.com [Internet]. Fox61. 2017 [cited 2020 Mar 12]. Available from: https://www.fox61.com/article/news/local/outreach/awareness-months/ apparent-drug-overdose-leads-to-hazmat-situation-in-hartford/520-45840c2 e-5529-4590-9272-079da968362c.

26. National Institute for Occupational Safety and Health. CDC - the Emergency Response Safety and Health Database: incapacitating agent: FENTANYL NIOSH [Internet]. Natl. Inst. Occup. Saf. Heal. 2011 [cited 2020 Mar 12]. Available from: https://www.cdc.gov/niosh/ershdb/ emergencyresponsecard_29750022.html.

27. Colloca L. Nocebo effects can make you feel pain. Science (80-. ). American Association for the Advancement of Science; 2017. p. 44.

28. Petrie K, Milligan-Saville J, Gayed A, Deady M, Phelps A, Dell L, et al. Prevalence of PTSD and common mental disorders amongst ambulance personnel: a systematic review and meta-analysis. Soc Psychiatry Psychiatr Epidemiol. Dr. Dietrich Steinkopff Verlag GmbH and Co. KG. 2018;53:897-909.

29. Winograd RP, Werner KB, Green L, Phillips S, Armbruster J, Paul R. Concerns that an opioid antidote could "make things worse": profiles of risk compensation beliefs using the Naloxone-Related Risk Compensation Beliefs (NaRRC-B) scale. Subst Abus. Routledge; 2019;

30. Winograd RP, Stringfellow EJ, Phillips SK, Wood CA. Overdose education training can exacerbate some law enforcement officers' negative attitudes towards overdose victims. Manuscr Submitt Publ. 2020;

31. DEA Headquarters. DEA issues carfentanil warning to police and public [Internet]. 2016. Available from: https://www.dea.gov/press-releases/2016/ 09/22/dea-issues-carfentanil-warning-police-and-public.

32. Beletsky L, Agrawal A, Moreau B, Kumar P, Weiss-Laxer N, Heimer R. Police training to align law enforcement and HIV prevention: preliminary evidence from the field. Am J Public Health. American Public Health Association. 2011;101:2012-5.

33. Somerville NJ, O'Donnell J, Gladden RM, Zibbell JE, Green TC, Younkin M, et al. Characteristics of fentanyl overdose - Massachusetts, 2014-2016. Morb. Mortal. Wkly. Rep. Department of Health and Human Services; 2017. p. 382-6.

\section{Publisher's Note}

Springer Nature remains neutral with regard to jurisdictional claims in published maps and institutional affiliations.

Ready to submit your research? Choose BMC and benefit from:

- fast, convenient online submission

- thorough peer review by experienced researchers in your field

- rapid publication on acceptance

- support for research data, including large and complex data types

- gold Open Access which fosters wider collaboration and increased citations

- maximum visibility for your research: over $100 \mathrm{M}$ website views per year

At $\mathrm{BMC}$, research is always in progress.

Learn more biomedcentral.com/submissions 